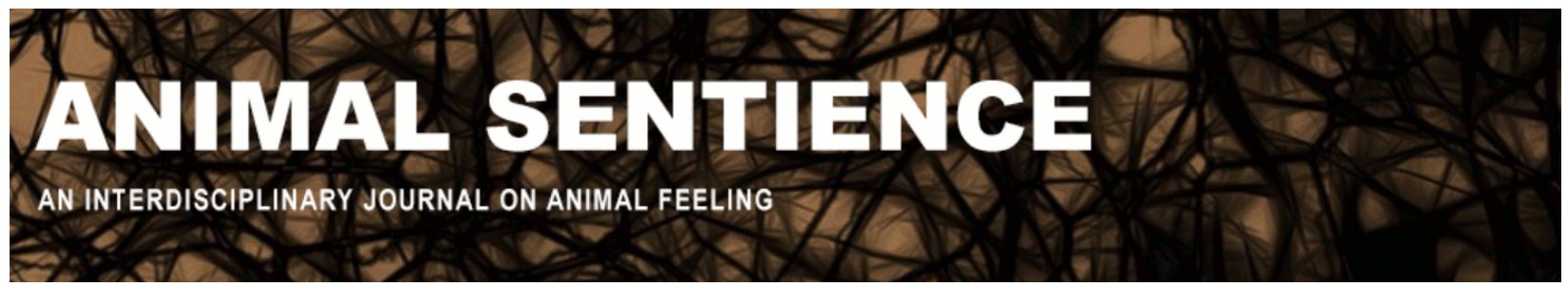

Rey Planellas, Sonia (2017) The emotional brain of fish. Animal Sentience 13(11) DOI: $10.51291 / 2377-7478.1248$

Date of submission: $2017-11-10$

Date of acceptance: 2017-11-15

(c) (i)




\title{
The emotional brain of fish
}

Commentary on Woodruff on Fish feel

\author{
Sonia Rey Planellas \\ Institute of Aquaculture, Faculty of Natural Sciences \\ University of Stirling, UK
}

\begin{abstract}
Woodruff (2017) analyzes structural homologies and functional equivalences between the brains of mammals and fish to understand where sentience and social cognition might reside in teleosts. He compares neuroanatomical, neurophysiological and behavioural correlates. I discuss current advances in the study of fish cognitive abilities and emotions, and advocate an evolutionary approach to the underlying basis of sentience in teleosts.
\end{abstract}

Sonia Rey Planellas is a researcher at the Institute of Aquaculture at the University of Stirling. She is part of a multidisciplinary research group on fish behavior and welfare. She is interested in the individual differences in behavior (personalities), physiology, cognition and welfare of fish. www.stir.ac.uk/people/25264
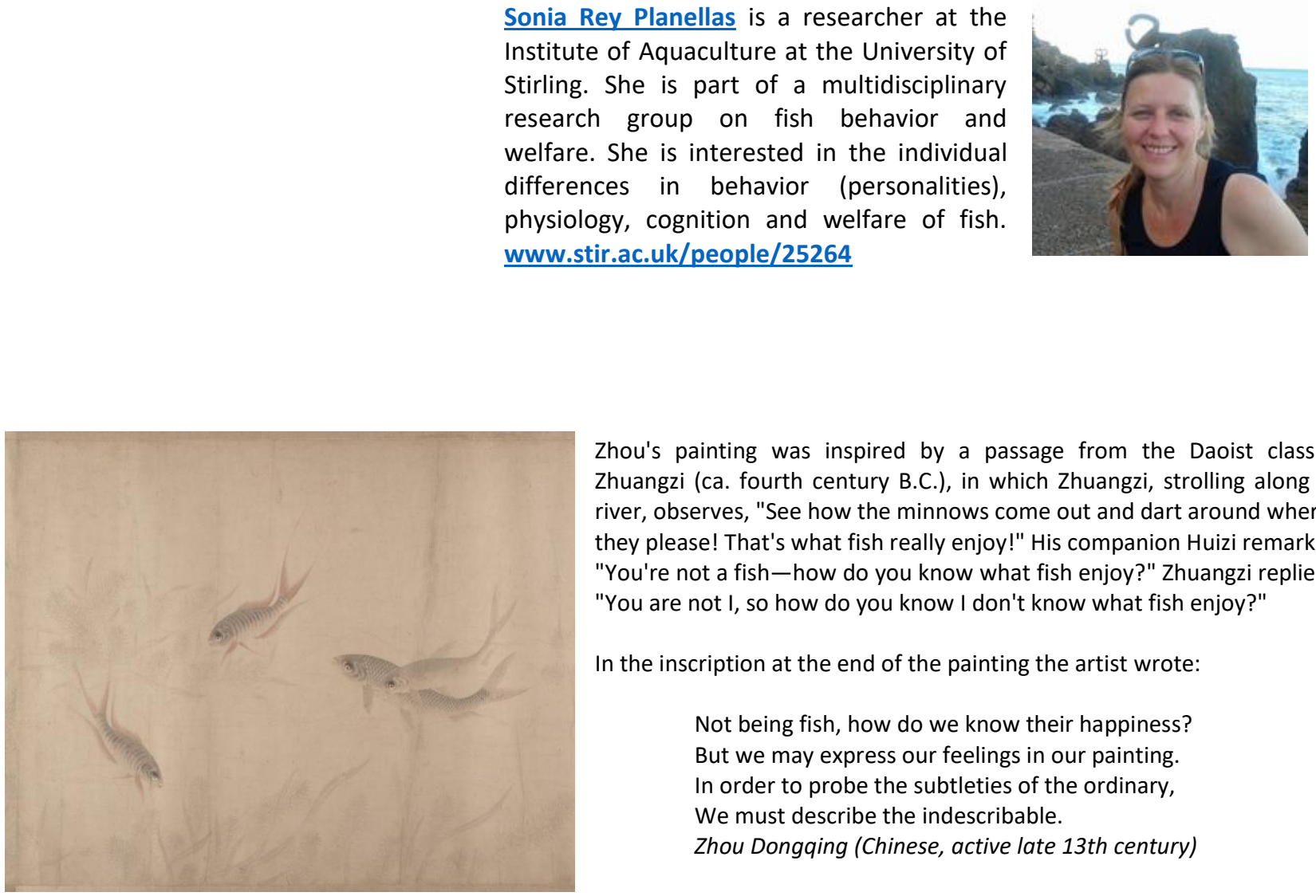

Zhou's painting was inspired by a passage from the Daoist classic Zhuangzi (ca. fourth century B.C.), in which Zhuangzi, strolling along a river, observes, "See how the minnows come out and dart around where they please! That's what fish really enjoy!" His companion Huizi remarks, "You're not a fish-how do you know what fish enjoy?" Zhuangzi replies, "You are not I, so how do you know I don't know what fish enjoy?"

In the inscription at the end of the painting the artist wrote:
Not being fish, how do we know their happiness? But we may express our feelings in our painting. In order to probe the subtleties of the ordinary, We must describe the indescribable.
Zhou Dongqing (Chinese, active late 13th century)

On the controversial topic of animal sentience, two different questions need to be asked: are animals sentient? and do they have emotions? In humans, emotions are also called feelings. Their study is complicated by definitional and conceptual difficulties (LeDoux 2012). From an evolutionary viewpoint, emotions can be seen as a survival tool, as they reflect conserved functions and circuits that are shared by humans and other animals (e.g., fear system, play, etc.) 
(Anderson et al. 2014, Panksepp 2005). LeDoux integrated and conceptualised these ideas as a survival circuit that includes emotions, motivation, reinforcement and arousal, in a natural evolutionary progression of increasing complexity to finally arrive at mammals and humans.

Cabanac et al. (2009) adopted an anatomical and functional approach to the phylogeny of consciousness. Woodruff (2017) highlights the structural homology and functional equivalence between forebrain structures in fish and other vertebrates, concluding that fish brains are remarkably similar in organisation to those of other vertebrates. Particularly relevant are the mammalian amygdala (involved in the generation of emotion) and hippocampus (involved in learning and spatial memory), which are homologous and functionally equivalent to the dorsomedial and dorsolateral telencephalic pallium of the fish forebrain (Portavella et al. 2004, Demski 2013). Cortisol and serotonin in these brain regions in Nile Tilapia (Oreochromis niloticus) increase after exposure to a stressful situation (confinement) (Silva et al. 2015).

In teleosts, it has been confirmed that similar neurotransmitters (e.g., dopamine) have to be in place to perform similar functions (Messias et al. 2015). Two extensively studied neuroendocrine systems should be highlighted in fish: (1) the hypothalamic-pituitary-interrenal axis (HPI) and (2) the teleost brain serotonergic system.

The HPI regulates acute stress responses, among other functions. Anaesthetics reduce or block activation of the HPI associated with different stressors (Iversen et al. 2003). Sedation in fish reduces consciousness and modulates stress responses (Ross and Ross, 2008).

The serotonergic system also plays an important role in the expression of emotions in vertebrates. Serotonin or 5-HT (5-hydroxytryptamine) serves multiple functions in the vertebrate brain including the control of emotions, stress coping responses and aggression. Serotonin has been extensively studied; it is related to sentience and by extension to consciousness in mammals and other vertebrates (LeDoux 2012). It appears to have a key role in the expression and modulation of emotion-like states in fish, especially long-term responses to social stress (Backstrom and Winberg 2017). The neurochemistry is so well-conserved in vertebrates that the zebrafish model (Danio rerio) is extensively used to test new medications for anxiety and depression in translational studies (Pitmann 2014). The dopaminergic system also has a significant role in emotional learning and memory (Messias 2015).

Behavioural signs of consciousness: Play, pleasure and sleep in fish. The signs of consciousness Cabanac et al. (2009) considered were emotional states or the behavioural expression of emotion, the search for sensory pleasure, animal play, and the presence of REM sleep. Studies have shown some of these signs in fish. The expression of emotion in the form of emotional fever (or stress-induced hyperthermia) has been reported in zebrafish (Rey et al. 2015): fish moved to a higher temperature area of the tank to raise their body temperature after stressful handling. The most likely area of the brain involved is the preoptic area (POA) which is also involved in the expression of behavioural fever induced by a bacterial or viral infection (Boltaña et al. 2013) triggered by an increase in plasma-borne inflammatory prostaglandins.

The capacity for emotional fever was one of the signs of the emergence of consciousness in vertebrate phylogeny (Cabanac et al. 2009). Other signs such as play have been demonstrated in fish. Burghardt et al. (2014) reported that fish display behaviour that met the five criteria for 
play. Pleasurable emotions or the avoidance of unpleasant emotions in fish has also been reported by the Oliveira lab (Cerqueira et al. 2017) with neuromolecular studies indicating distinctive affective states regulated by the individual's perception of environmental stimuli. The latest research on zebrafish did not provide evidence of REM sleep (Árnason et al. 2015), but current technology could be a limitation. More research should be conducted on refining the methods of recording REM sleep or its homologues in fish.

From an evolutionary perspective, and based on the evidence mentioned above, emotion probably represents a driving force for evolutionary change and adaptation. With current technical and analytical advances, evidence of consciousness in fish could soon be extended. Integrated behavioural and neuromolecular mapping of neurogenomic states in relevant brain regions will increase our understanding of the molecular regulation of behaviour. Further research is vitally important for a coherent approach to policy-making and regulation for the welfare of fish.

\section{References}

Anderson, D. J., \& Adolphs, R. (2014) A framework for studying emotions across species. Cell, 157, 187-200.

Árnason, B. B., Porsteinsson, H., \& Karlsson, K. AE. (2015) Absence of rapid eye movements during sleep in adult zebrafish. Behavioural Brain Research, 291, 189-194.

DOI:10.1016/j.bbr.2015.05.017

Backström, T., \& Winberg, S. (2017) Serotonin coordinates responses to social stress-What we can learn from fish. Frontiers in Neuroscience, 11, 595.

Boltaña, S., Rey, S., Roher, N., Vargas, R., Huerta, M., Huntingford, F.A., Goetz, F.W., Moore, J., Garcia-Valtanen, P., Estepa, A., \& Mackenzie, S. (2013) Behavioural fever is a synergic signal amplifying the innate immune response. Proceedings of the Royal Society B, 280, 20131381.

Burghardt, G. M., Dinets, V., \& Murphy, J. B. (2015) Highly repetitive object play in a cichlid fish (Tropheus duboisi ) (Ed. L. Ebensperger). Ethology, 121, 38-44.

Cabanac, M., Cabanac, A. J., \& Parent, A. (2009) The emergence of consciousness in phylogeny. Behavioural Brain Research, 198, 267-272.

Cerqueira, M., Millot, S., Castanheira, M. F., Félix, A. S., Silva, T., Oliveira, G. A., Oliveira, C. C., Martins, C. I. M., \& Oliveira, R. F. (2017) Cognitive appraisal of environmental stimuli induces emotion-like states in fish. Scientific Reports, 7, 13181.

Demski, L. S. (2013). The pallium and mind/behavior relationships in teleost fishes. Brain Behaviour and Evolution, 82, 31-44. doi:10.1159/000351994

Iversen, M., Finstad, B., McKinley, R. S., \& Eliassen, R. A. (2003). The efficacy of metomidate, clove oil, Aqui-S and Benzoak as anaesthetics in Atlantic salmon (Salmo salar L.) smolts, and their potential stress-reducing capacity. Aquaculture, 221(1-4), 549-566.

doi:10.1016/S0044-8486(03)00111-X

LeDoux, J. (2012). Perspective rethinking the emotional brain. Neuron, 73, 653-676.

doi:10.1016/j.neuron.2012.02.004 
Messias, J.P.M., Santos, T.P., Pinto, M., \& Soares, M.C. (2016) Stimulation of dopamine D 1 receptor improves learning capacity in cooperating cleaner fish. Proceedings of the Royal Society B: Biological Sciences, 283, 20152272.

Panksepp, J. (2005) Affective consciousness: Core emotional feelings in animals and humans. Consciousness and Cognition, 14, 30-80.

Pittman J. T., \& Lott C. S. (2014) Startle response memory and hippocampal changes in adult zebrafish pharmacologically-induced to exhibit anxiety/depression-like behaviors. Physiology \& Behavior, 123, 174-179. DOI:10.1016/J.PHYSBEH.2013.10.023

Portavella, M., Torres, B., \& Salas, C. (2004) Avoidance response in goldfish: Emotional and temporal involvement of medial and lateral telencephalic pallium. The Journal of Neuroscience, 24, 2335-2342. DOI:10.1523/JNEUROSCI.4930-03.2004

Rey, S., Huntingford, F. A., Boltana, S., Vargas, R., Knowles, T. G., \& Mackenzie, S. (2015) Fish can show emotional fever: stress-induced hyperthermia in zebrafish. Proceedings of the Royal Society 282: 20152266. DOI: 10.1098/rspb.2015.2266

Ross, L. G., \& Ross, B. (Eds.). (2008). Anaesthetic and sedative techniques for aquatic animals. Oxford, UK: Blackwell Publishing Ltd. DOI:10.1002/9781444302264

Silva, P. I. M., Martins, C. I. M., Khan, U. W., Gjøen, H. M., Øverli, Ø., \& Höglund, E. (2015) Stress and fear responses in the teleost pallium. Physiology \& Behavior, 141, 17-22.

DOI:10.1016/j.physbeh.2014.12.020

Woodruff, M. L. (2017). Consciousness in teleosts: There is something it feels like to be a fish. Animal Sentience 13(1). 


\section{ANIMAL CONSCIOUSNESS}

On November 17-18, 2017, the NYU Center for Mind, Brain and Consciousness, the NYU Center for Bioethics, and NYU Animal Studies will host a conference on Animal Consciousness.

This conference will bring together philosophers and scientists to discuss questions such as: Are invertebrates conscious? Do fish feel pain? Are nonhuman mammals self-conscious? How did consciousness evolve? How does research on animal consciousness affect the ethical treatment of animals? What is the impact of issues about animal consciousness on theories of consciousness and vice versa? What are the best methods for assessing consciousness in nonhuman animals?

\section{Speakers and panelists include:}

Colin Allen (University of Pittsburgh, Department of History \& Philosophy of Science), Andrew Barron (Macquarie, Cognitive Neuroethology), Victoria Braithwaite (Penn State, Biology), Peter Carruthers (Maryland, Philosophy), Marian Dawkins (Oxford, Zoology), Dan Dennett (Tufts, Philosophy), David Edelman (San Diego, Neuroscience),

Todd Feinberg (Mt. Sinai, Neurology), Peter Godfey-Smith (Sydney, Philosophy), Lori Gruen (Wesleyan, Philosophy), Brian Hare (Duke, Evolutionary Anthropology), Stevan Harnad (Montreal, Cognitive Science), Eva Jablonka (Tel Aviv, Cohn Institute), Björn Merker (Neuroscience), Diana Reiss (Hunter,

Psychology), Peter Singer (Princeton, Philosophy), Michael Tye (Texas, Philosophy)

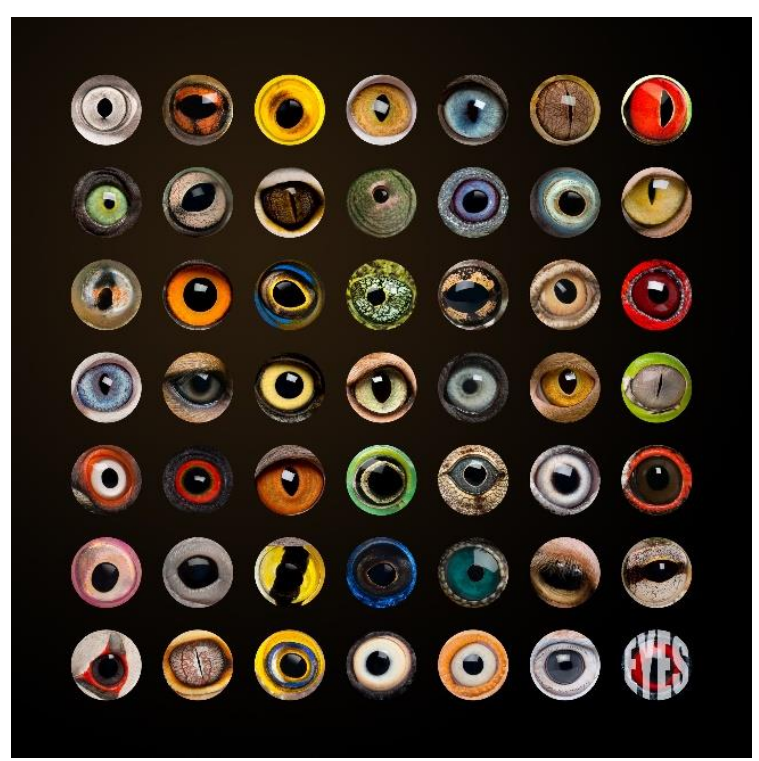

Organizers: Ned Block, David Chalmers, Dale Jamieson, S. Matthew Liao.

The conference will run from 9am on Friday November 17 to $6 \mathrm{pm}$ on Saturday November 18 at the NYU Cantor Film Center (36 E 8th St).

Friday sessions will include "Invertebrates and the evolution of consciousness", "Do fish feel pain?", and "Animal consciousness and ethics".

Saturday sessions will include "Animal self-consciousness", "Animal consciousness and theories of consciousness", and a panel discussion.

A detailed schedule will be circulated closer to the conference date.

Registration is free but required.

\section{Register here.}

\section{See also the conference website}

